\title{
Title: Being occupied with what matters in advanced age
}

\section{Abstract}

This article illuminates one key finding of an interpretive phenomenological study that brought an occupational lens to exploring how elders experience ageing in their everyday lives. Fifteen community-dwelling, New Zealand elders aged 71 to 97, 4 Maori and 11 nonMaori, were purposively recruited. Data were gathered through individual interviews focused on stories of everyday moments and photographs of the participant's hands only while engaged in doing a chosen occupation. Discrete stories were drawn from the narrative data and interpreted, guided by Gadamerian hermeneutics and Heideggerian phenomenology. The notion of 'doing what matters' emerged as participants spoke of having one occupation that was of primary importance to them. This one compelling pursuit showed as an enduring interest over time, illuminating the temporal unity of past, present and future in advanced age. Accordingly, the boundaries of researching occupational engagement in advanced age ought to be redefined. Instead of a current emphasis on understanding elders’ participation in daily activities, activity categories and patterns, occupational science research might deepen the focus to understand how engagement in subjectively compelling occupations is associated with ageing well and longevity.

\section{Keywords}

Older adults, interpretive phenomenology, everyday occupations, ageing well 


\section{Introduction}

Born in 1912, Davina Whitehouse begins her account of everyday life in advanced age by saying, "I don’t really concentrate much on growing old, I just concentrate on living and being and doing” (Maclean, 2000, p. 15). Occupational science is concerned with the study of what people do and understanding the complexity of human engagement in occupations (F.

A. Clark et al., 1991; Wilcock, 1991). While the scope of what the field includes is varied and still growing (Hocking, 2009), occupational science "is ultimately concerned with the exploration of human occupation in its totality” (Molke, Laliberte-Rudman, \& Polatajko, 2004, p. 277).

\section{Doing Physical Leisure Time Occupations}

Numerous multidisciplinary studies are congruent with occupational science in their exploration of what older adults do and their patterns of time use. As life goes on, participation in a range of everyday occupations is associated with ageing well (Menec, 2003), although occupations tend to become more sedentary (Ashe, Miller, Eng, \& Noreau, 2009; Paillard-Borg, Wang, Winblad, \& Fratiglioni, 2009). Accordingly, the health consequences of older adults' low participation rates in leisure time physical activities is receiving particular attention (Jacobs et al., 2008). For example, doing fewer physically demanding leisure occupations in advanced age is associated with higher rates of depressive symptoms (Hamer, Molloy, de Oliveira, \& Demakakos, 2009). As few as a quarter (Hamer et al., 2009) of older adults meet the recommended American guidelines of at least 30 minutes of moderately intensive activity on 5 occasions each week (Ashe et al., 2009). Similarly, researchers in five European countries and Canada respectively (Ashe et al., 2009; Gagliardi et al., 2007) found that while participation in occupations like walking and gardening is relatively high, few participate in sports or resistance exercises. Complicating the picture, scientific and subjective understandings of health-promoting activities may differ. In Grant's 
(2008) study of older New Zealanders, being busy rather than doing physical exercise per se was considered healthy activity. Furthermore, a large cohort study of older Americans revealed that participation in social occupations, such as going to the cinema and playing card or board games, and productive occupations, such as gardening, preparing meals or shopping, conferred the same survival benefits over 13 years as fitness-based activities (Glass, Mendes de Leon, Marottoli, \& Berkman, 1999). This suggests there is more to understand about what occupations promote healthfulness in advanced age.

\section{Everyday Occupations and Ageing Well}

Engaging in social occupations is positively associated with better health and functional outcomes as well as survival (Bath \& Deeg, 2005; Dahan-Oliel, Gelinas, \& Mazer, 2008; Fitzpatrick, 2009; Menec, 2003). For German elders, time spent talking with friends on the phone and in-person conferred a significant survival advantage over three years. Spending time in active leisure as well as watching television or listening to the radio also related positively to survival, but less so than socialising with friends (Maier \& Klumb, 2005). Accordingly, it is strongly argued that engaging in the social environment reduces the disability associated with ageing and is therefore protective of better health (Mendes de Leon, Glass, \& Berkman, 2003). However, Bennett (2005) found engaging in social occupations was highly predictive of subjective, self-rated health but not objective measures of health. And, compared with older women, men may benefit more from doing active, solitary occupations such as woodwork or gardening (Lennartson \& Silverstein, 2001). Complicating the picture are the varying ways social participation is conceptualised and measured (Mendes de Leon, 2005). This means the health promoting mechanisms and affects of social participation are not well understood. 
In an attempt to more clearly understand the health promoting mechanisms of leisure occupations, a number of international studies have explored the relationship between occupational engagement over time and ageing well (Akbaraly et al., 2009; Chen \& Fu, 2008; Dodge et al., 2008; Droogleever Fortuijn et al., 2006; Haggblom-Kronlof \& Sonn, 2005; Menec, 2003; Nilsson, Lofgren, Fisher, \& Bernspang, 2006; Paillard-Borg et al., 2009; Simone \& Haas, 2009; Strain, Grabusic, Searle, \& Dunn, 2002). In the Aging in Manitoba study, Menec (2003) used a 21-item leisure activity checklist to examine the relationship between overall participation levels, as well as doing particular occupations, and everyday function, wellbeing and mortality. Elders [n=1439] with higher levels of activity were more likely to survive over 6 years. Solitary leisure engagement in handwork hobbies, reading, writing, music or art was associated with greater happiness, as was doing productive activities such as light housework and gardening, and spending time in social groups. Furthermore, even though activity levels and function decreased over time, no corresponding decline in happiness occurred (Menec, 2003). This suggests happiness in advanced age is associated with something other than the continuance of doing a wide range of leisure occupations. Interestingly, leisure participation rates are highest for reading and watching television or digital video discs (DVD) for Swedish elders (Paillard-Borg et al., 2009), older

Canadians (Strain et al., 2002), Taiwanese (Chen \& Fu, 2008), and Japanese elders (Dodge et al., 2008). Yet participation rates do not indicate what occupations matter most to the person.

\section{Doing Personally Valued Occupations}

Where studies have explored engagement in personally meaningful occupations, participation is found to be positively related to leisure enjoyment for elder Taiwanese (Chen \& Fu, 2008), “psychological well-being and health-related quality of life” (Eakman, Carlson, \& Clark, 2010, p. 313) for American seniors, and life satisfaction six European countries (Droogleever Fortuijn et al., 2006), as well as providing a purpose for being (Grant, 2008). Similarly, in a 
randomised controlled trial with American seniors, Clark et al. (1997) found those who redesigned their lifestyles to include more personally meaningful occupations reported increased vitality and participation in social and physical occupations. In contrast, a study of older Australians revealed no statistically significant associations between doing personally valued occupations and life satisfaction (Stanley, 1995). No equivalent literature on older New Zealanders was found. Additionally, the existing research predominantly uses activity checklists to measure participation across multiple activities or activity categories. A significant gap exists in research which brings a non-prescriptive, occupational perspective to exploring what older adults do.

Therefore, this study asked, what is elders' experience of ageing in their everyday lives? It enabled the participants to reveal engagement in occupations of choice. This paper focuses on one aspect of the findings; the stories about doing the one occupation that mattered most.

\section{Methodology and Methods}

The New Zealand Northern X Regional Ethics Committee granted ethics approval for gathering narrative data, and subsequently photographic data. As a non-Maori researcher, integrity of working with elder Maori was promoted through partnership with an established Maori community health service, Te Puna Hauora.

Interpretive phenomenology was chosen as the methodology. Gadamerian hermeneutics (1975/2004) provided the broad philosophical horizon. It informed the methods of interpreting the research text through questioning, staying open to possibilities of meaning, and of letting the text speak in its own way. Heideggerian phenomenology (1927/1962) informed the approaches to gathering the data and thinking about the phenomenon of interest. Heidegger's interpretive phenomenology seeks to understand phenomena that are not selfevident. It informs a mode of inquiry which lets a thing that is ordinarily concealed in some 
way "show itself” (Heidegger, 1927/1962, p. 58). Hence, I aimed to uncover the lived experience of being in the everyday in advanced age; something that is usually taken-forgranted. My pre-understandings about being aged and everyday occupations were considered as they came into play rather than being bracketed.

\section{Recruitment}

Non-probability purposive recruitment of 11 non-Maori elders, aged 80 and over, and 4 Maori, aged 70 and over, was conducted using the general electoral roll for Auckland's North Shore. The age inclusion difference reflects the average 10-year disparity in longevity for Maori (Statistics New Zealand, 2003). The 7 men and 8 women purposively selected were community-dwelling across a range of suburbs with higher and lower than national average levels of education, income and European ethnicity (Statistics New Zealand). Potential nonMaori participants were sent a personally addressed letter containing information about the study and a consent form. Those who did not return a signed consent form were not followedup. Guided by culturally appropriate methods, Maori participants were recruited in partnership with the Kaumatua (respected elder) at Te Puna Hauora. He identified elders who met the inclusion criteria, delivered information about the study, and gained written consent before I was introduced as the researcher. To allow for concurrent data gathering and analysis, participants were recruited one at a time. All consented to being interviewed at home. An overview of participants is presented in Table 1.

\section{Data Gathering}

Philosophically, it was assumed the phenomenon of interest, being in the everyday in advanced age, would “manifest itself in experience” (Gadamer, 1975/2004, p. 57) and therefore appear in the participants' stories of going about their day. Individual interviews of up to 2 hours were conducted. To enable completion of data gathering or data elaboration, 
eight second interviews were conducted. Open questions, such as "tell me about yesterday," invited participants to engage in a conversational mode of telling everyday stories. Probing questions enabled rich data to be elicited. Consistent with phenomenology, participants were encouraged to recount particular moments and events, as they were lived (van Manen, 2001). For example, if gardening came up in conversation, I might ask "tell me about the last time you were in the garden.” Early on I noticed how the participants' hands seemed to disclose things about occupations and ageing. Subsequently, at the end of each interview, participants were given the opportunity to have a photograph taken, of their hands only, doing an occupation of choice. The rich visual data (Emmison, 2004) supplemented the narrative data. Compellingly, each participant immediately knew what he or she wanted to do for the photograph. Where this was not feasible, the person chose another occupation of interest. For example, Madge [95] loved music and playing the piano but did not wish to play in front of me. Instead she chose tatting, a handcraft she had continued intermittently since young adulthood. I kept a reflexive diary of observations and thoughts, recorded immediately after each interview, and throughout the research process.

All interviews were digitally recorded and transcribed verbatim. Participants self-chose a pseudonym. The interview texts revealed the messiness of conversations (Caelli, 2001). The stories’ essential meanings were illuminated by tidying the grammatical structure and removing repetition unless it added depth the meaning (Caelli). Each participant's collated stories were returned for verification of accuracy and completeness. Copies of the photographs became a way of giving something back. To illustrate, Ella [93] had put aside her tapestry of the Last Supper prior to hip surgery some months ago. In bringing it out to work on for her photograph, she excitedly told me "it has come back.” It enabled Ella to reconnect with something lost. 
[insert Table 1 about here]

\section{Data Analysis}

In accordance with the methodology, gathering and analysing the text occurred concurrently; one informing the other (van Manen, 2001). Guided by hermeneutics, the research text (all stories and photographs) was interpreted through reading and rereading, by thinking, and by writing and rewriting. It was a way of 'listening' to what the parts of and the whole text was saying (Gadamer, 1975/2004); of hearing how meanings were brought into the stories through evocative, idiomatic, and metaphoric language. For example, when Margaret said "I am mad about art," her use of the words "mad about" pointed to more than simply having an interest in artistic painting. Questions were asked of the text such as "what is s/he saying here?” The Kaumatua read and guided my interpretations of the Maori elder’s stories to ensure the cultural meanings were respected. Dwelling upon the photographic images brought a visual text to the interpretive process. The meaning of doing lit up within the context of each participant's stories. For example, Tom had already spoken of his career as a sail maker. He chose working on one of his homemade model boats for his photograph. The images helped me to 'see' the meaning of having at least one enduring occupation that mattered.

Interpreting the text, engaging in the 'hermeneutic circle,' moved from dwelling upon each participant's stories and photographic image, the subjective, to a broader reflection of meanings across the whole research text (Gadamer). The ontological meanings were uncovered through interpreting what the whole text was saying; and of wondering about what appeared and what remained hidden (van Manen, 2001). A full literature review was conducted after data analysis. Congruent with the guiding philosophies, it spanned poetry, novels, newspapers and scholarly journals. 


\section{Findings: Doing What Matters}

The stories presented are selected for their poignancy in illustrating the notion of 'doing what matters' in advanced age. Other interpretive themes published elsewhere (Wright-St Clair, Kerse, \& Smythe, 2011). Philosophical notions are woven through the interpretations, highlighting the ontological nature of the phenomenon of being in the everyday in advanced age.

In conversation, the participants spoke of doing the mundane, always-there things in their day, of responding to things which unexpectedly appeared and of making time to do things which particularly interested them. Spontaneously in the research conversations, the topic would come up of one thing, one occupation, which roused a passion for doing more than other things. Margaret [80] said:

I love meeting people. I love seeing the things [art work] I have read about. I am mad about art. That's my big thing. Well, I went to Elam in 1940 and I have always painted....And then of course I forgot all about art when I was having my children....I get great joy in painting but I haven't done any for really the last five years. I am concentrating on my grandkids. Now I do and I don't paint. I do when people say, you've got to have something in the exhibition and then I get cracking. Life's very busy. Two friends did all the organising for our school reunion last week, and I thought I know what I will do; I will paint them each a picture. That was in my mind today actually. I know what I am going to do. I will have to get cracking and I will send them a nice painting each [Margaret].

Similarly, the others each happened to speak of one thing they never wanted to stop doing. To illustrate, Madge [95] mentioned: 
I am still able to take a big part in music. Music is still my main thing...I do like my music; I think I would miss that as much as anything. Yes I would hate not to have music. What else is there for me?

And Frank [97] commented:

I have always gardened. I suppose you would almost say gardening's my greatest interest; and re-rooting things. It's just the fun of producing these things. It gives me something to do, not chucking everything away. If I couldn't garden, ahhhhh, then I would start to get old...Oh yes. I would be lost without the garden.

This one thing; this one occupation, was variously spoken of as being my big thing; my main thing; and my greatest interest. Each person points to the one pursuit as reflecting an essential-ness of who they are. The one occupation showed as an enduring interest over time; there was Margaret’s painting from her days as an arts student, Madge’s music from her childhood days with family gathered around the piano and singing, and Frank's gardening from the age of six when helping his mother. And in expressing, what else is there for me or I would be lost without the garden each uncovers the hope to continue the occupation into the future. Thus, engaging in this one pursuit shows 'who I have been,' 'who I am now' and 'who I will be.' It illuminates the temporal unity of past, present and future through occupational engagement in advanced age. Thus, in their own way, each person brings into words, I am an artist; I am a musician; I am a gardener. Interpretively, we hear the hermeneutic 'as' in play. That is, how the one pursuit is talked about and persistently referred back to "lets something be seen as something” (Heidegger, 1927/1962, p. 57). The words assert one 'as' — the one thing as 'my greatest interest.' Whereas interpretation reveals a more primordial 'as' — the one thing as being 'me;' I am this person. 
Listening to stories told by elder Maori revealed a further dimension of meaning. Matelot [74] shared:

A good day is when I have got something to do or somebody rings me up to do something. Because I am a kaumatua, I am called on to go and do things. It is landed on my shoulders....If I couldn't go, well I suppose that is not the day I am looking forward to actually. No. I would just sit at home I suppose and that is about all.

When he says a good day is one when the call to do something comes because he is a kaumatua, Matelot communicates the depth of respect he is afforded as elder within the Maori community. His knowledge in Maori language, traditional customs and rules is valued and called upon for ceremonial functions which are the spiritual reserve of kaumatua. Through saying it is landed on my shoulders, he signifies an observance of the customary passing on of kaumatua functions. Those before him handed down responsibilities to him, as he will do to someone else in the future. His place as elder takes precedence over other things within his everyday world. Philosophically the notion of mana ${ }^{1}$ Maori motuhake ${ }^{2}$ offers a deeper understanding. It has its foundations in Maori resistance to full assimilation as a colonised people. Through the twentieth century, new urban marae ${ }^{3}$ were established as Maori migrated from their rural homelands to work in the industrialising cities. "Accordingly, for landless Maori, the marae was their remaining turangawaewae ${ }^{4}$ on which to hang their identity as the indigenous people” (Walker, 1990, p. 187). Contemporary affiliation with marae and other Maori associations perpetuates traditional knowledge and customs by way of passing responsibilities on to kaumatua and kuia, the male and female elders (Walker). In

\footnotetext{
${ }^{1}$ Mana is the Maori word meaning “authority, power, prestige” (Walker, 1990, p. 296).

${ }^{2}$ Motuhake in Maori means “discrete, separate, independent” (Walker, 1990, p. 296).

${ }^{3}$ Marae is the "community meeting place where formal greetings and discussions take place in front of the wharenui” [meeting house] (Moorfield, 1988, p. 151).

${ }^{4}$ Turangawaewae means "standing in the tribe” (Walker, 1990, p. 298).
} 
closing, Matelot tells of not looking forward to a time of not being able to go as kaumatua. His words emphasise the purposefulness of contributing to the greater spiritual and cultural world of Maori.

Collectively, the words used when talking about the one compelling occupation illuminate an intensity of emotions, such as I get great joy in painting; I would hate not to have music; I would be lost without the garden; and that is not the day I am looking forward to. The language reveals that doing this one occupation matters to the person in their advanced age. It makes being in the everyday worthwhile.

\section{Discussion}

Predominantly, previous studies of what older adults do have been quantitative in nature, and prescriptive in relation to the occupations or activities included. The notion of "doing what matters” emerged from this interpretive phenomenological research through listening to Maori and non-Maori elders' stories of going about their day. Richness and diversity showed in the occupations chosen for the participants’ photographs; from making things, like a complex tapestry to a replica model boat; solving puzzles, like doing Sudoku or crosswords; caring for things, like a pet or the garden; playing things like cards or darts; to being creative, like playing the piano or writing poetry. In a phenomenological study of ageing in Finland, surprise was expressed at the participants’ creativity and level of engagement (Heikkinen, 2004). Yet this suggests a pre-understanding of what older adults ought to occupy their time with. Being the age they were, this study's participants had most of their lives behind them. As such, they came into each day having already experienced innumerable other days and events, and having occupied their time with many things throughout their life course. And while the everyday, being what it is, meant tomorrow might be much like today or yesterday, the importance of always having things to do, as well as at least one occupation to look 
forward to, showed through. Engaging in and caring about one enduring pursuit evoked a deep, intense sense of identity; of being 'me' in the world. Explained ontologically, “'one is' what one does” (Heidegger, 1927/1962, p. 283). In the same vein, Kaufman (2000) found that elders understood themselves through a continuity of already established 'themes' of engaging. Purportedly, such thematic, continuity is central to contentment, irrespective of the losses and limitations that come with age. While Petry (2003) also found older Swiss women living alone wanted "to do and continue to do what they have always done” (p. 56), she interpreted this in the context of wanting to remain functionally independent.

How the participants in this study spoke about engaging in one enduring, compelling occupation revealed being connected to the past, being fully engaged in the present and being hopeful toward the future. Having the one thing that gives great joy is a reason for being in the everyday. So, even though Margaret mentioned I haven't done any for really the last five years, she is still an artist. The possibility of painting is still there in her everyday. Open questioning with the participants meant they freely chose how they spoke about the things they did. Interestingly, when elders in an Australian time use study were asked to record the percentage of time spent doing 'valued' occupations, fewer than 50\% did so. From their comments, it seems the notion was not an easy one for them to understand (Stanley, 1995). This points to a concern that checklists or questionnaires may in reality conceal the occupational phenomena of interest. Furthermore, reporting occupational participation rates, like the percentage who watch television or read (Chen \& Fu, 2008; Dodge et al., 2008; Paillard-Borg et al., 2009; Strain et al., 2002), may cover over understanding of doing occupations that matter.

In advanced age, while abilities or interests may change, or be lost, having the one engaging pursuit seems to deliver a sense of stability to who I am and what I do. This interpretation is 
congruent with Atchely’s (1989) proposal that engagement in the familiar is comforting and provides a sense of order and direction in advanced age. For elder Maori, the stability of who I am and what I do was steeped in tribal meaning. Similarly, in a recent study of Maori elders' health, participants reported an increased responsibility to take up marae-based activities. Being called upon as elder was at times experienced as burdensome; yet this was balanced out by the respect and everyday assistance they received within the Maori community (Waldon, 2004).

\section{Strengths and Limitations}

Through including Maori and non-Maori participants, rich data were gathered from indigenous and non-indigenous elders. How the stories were the same and different helped inform data interpretation. Furthermore, cultural integrity was promoted through the partnership with the Te Puna Hauora Kaumatua. Trustworthiness was primarily guided by Annells’ (1999) framework for evaluating phenomenological research.

More than half of those who received an invitation to participate in the study declined. How the stories of non-respondents might have been the same or different remains unknown. All participants resided within one electorate, albeit in demographically diverse communities. However, the region as a whole has higher than national average rates of post-secondary education, employment and income (Statistics New Zealand, 2003). It is unknown whether this context contributed to the elders' experiences. Finally, my presence brought its own limits. Who I am; my background, my experiences, my interests in occupational science and my presuppositions about everyday participation in advanced age all acted to limit what I asked, heard and interpreted. 


\section{Implications for Future Research}

There is a significant place for gaining a richer understanding of the causal interplay between being occupied in the day, particularly with one compelling occupation, and ageing well, health, and longevity? Accordingly, other pathways of inquiry would render different and important understandings. Only urban-dwelling elders participated in this study. Research which included those living in more remote situations may further illuminate the interplay of doing what matters to the person with health and survival.

\section{Conclusion}

The everyday stories told by New Zealand elder Maori and non-Maori revealed the salience of having at least one enduring, compelling pursuit in advanced age. Numerous studies document how older adults spend their time and their patterns of occupational engagement. However, the findings in this study suggest a redefining of the boundaries for understanding occupational engagement in advanced age might serve to uncover new knowledge. As the years go on, a day might call for countless mundane occupations, or hold significant time doing one or more occupations, yet this is not the same as doing something that matters. The boundary redefinition might occur in several ways; from enabling elders to freely define the nature of their occupational engagement, exploring the occupations in advanced age more deeply than broadly, to pushing out the methodological boundaries in a concerted effort to understand the relationship between occupations and ageing well. In advanced age, having an occupation that discloses who I have been, who I am and who I will be, matters.

\section{References}

Add :

Annells

Clark, F. A., Parham, D., Carlson, M. E., Frank, G., Jackson, J., Pierce, D., et al. (1991). Occupational science; Academic innovation in the service of occupational therapy's future. American Journal of Occupational Therapy, 45, 300-310.

Wilcock, A. A. (1991). Occupational science. British Journal of Occupational Therapy, 54, 297-300. 
Akbaraly, T. N., Portet, F., Fustinoni, S., Dartigues, J.-F., Artero, S., Touchon, J., ... Berr, C. (2009). Leisure activities and the risk of dementia in the elderly. Neurology, 73, 854861.

Ashe, M. C., Miller, W. C., Eng, J. J., \& Noreau, L. (2009). Older adults, chronic disease and leisure-time physical activity. Gerontology, 55, 64-72. doi:10.1159/000141518

Atchley, R. C. (1989). A continuity theory of normal aging. Gerontologist, 29(2), 183-190.

Bath, P. A., \& Deeg, D. (2005). Social engagement and health outcomes among older people: Introduction to a special section [Review]. European Journal of Ageing, 2, 24-30. doi:10.1007/s10433-005-0022-9

Bennett, K. M. (2005). Social engagment as a longitudinal predictor of objective and subjective health. European Journal of Ageing, 2, 48-55. doi:10.1007/s10433-0050501-z

Caelli, K. (2001). Engaging with phenomenology: Is it more of a challenge than it needs to be? Qualitative Health Research, 11(2), 273-281.

Chen, S.-Y., \& Fu, Y.-C. (2008). Leisure participation and enjoyment among the elderly: Individual characteristics and sociability. Educational Gerontology, 34, 871-889. doi:10.1080/03601270802115382

Clark, F., Azen, S. P., Zemke, R., Jackson, J., Carlson, M., Mandel, D., ... Lipson, L. (1997). Occupational therapy for independent-living older adults: A randomised controlled trial. Journal of the American Medical Association, 278(16), 1321-1326.

Clark, F. A., Parham, D., Carlson, M. E., Frank, G., Jackson, J., \& Pierce, D. (1991). Occupational scienc: Academic innovation in the service of occupational therapy's future. American Journal of Occupational Therapy, 45, 300-310.

Dahan-Oliel, N., Gelinas, I., \& Mazer, B. (2008). Social participation in the elderly: What does the literature tell us? Physical and Rehabilitation Medicine, 20(2), 159-176.

Dodge, H. H., Kita, Y., Takechi, H., Hayakawa, T., Ganguli, M., \& Ueshima, H. (2008). Healthy cognitive aging and leisure activities among the oldest old in Japan: Takashima study. Journal of Gerontology, 63A(11), 1193-1200.

Droogleever Fortuijn, J., van der Meer, M., Burholt, V., Ferring, D., Quattrini, S., Hallberg, I. R., ... Wenger, G. C. (2006). The activity patterns of older adults: A cross-sectional study in six European countries. Population, Space and Place, 12(5), 353-369. doi:10.1002/psp.422

Eakman, A. M., Carlson, M. E., \& Clark, F. A. (2010). The Meaningful Activity Participation Assessment: A measure of engagement in personally valued activities. International Journal of Aging and Human Development, 70(4), 299-317.

Emmison, M. (2004). The conceptualisation and analysis of visual data. In D. Silverman (Ed.), Qualitative research: Theory, method and practice (2nd ed., pp. 246-265). London: Sage Publications.

Fitzpatrick, T. R. (2009). The quality of dyadic relationships, leisure activities and health among older women. Health Care for Women International, 30, 1073-1092. doi:10.1080/07399330903199367

Gadamer, H.-G. (1975/2004). Truth and method (J. Weinsheimer \& D. G. Marshall, Trans., 2nd, Rev ed.). London: Continuum.

Gagliardi, C., Spazzafumo, L., Marcellini, F., Mollenkopf, H., Ruoppila, I., M, T., \& Szemann, Z. (2007). The outdoor mobility and leisure activities of older people in five European countries. Ageing and Society, 27, 683-700. doi:10.1017/S0144686X07006198

Glass, T. A., Mendes de Leon, C., Marottoli, R. A., \& Berkman, L. F. (1999). Population based study of social and productive activities as predictors of survival among elderly Americans. British Medical Journal, 319, 478-483. 
Grant, B. C. (2008). An insider's view of physical activity in later life. Psychology of Sport and Exercise, 9, 817-829.

Haggblom-Kronlof, G., \& Sonn, U. (2005). Interests that occupy 86-year-old persons living at home: Associations with functional ability, self-rated health and sociodemographic characteristics. Australian Occupational Therapy Journal, 53(3), 196-204. doi:10.1111/j.1440-1630.2005.00526.x

Hamer, M., Molloy, G. J., de Oliveira, C., \& Demakakos, P. (2009). Leisure time physical activity, risk of depressive symptoms, and inflammatory mediators: The English Longitudinal Study of Ageing. Psychoneuroendocrinology, 34, 1050-1055. doi:10.1016/j.psyneuen.2009.02.004

Heidegger, M. (1962). Being and time (J. Macquarrie \& E. Robinson, Trans., 7th ed.). Oxford, UK: Blackwell Publishers. (1927)

Heikkinen, R. L. (2004). The experience of ageing and advanced old age: A ten-year followup. Ageing and Society, 24(4), 567-582. doi:10.1017/S0144686X04001837

Hocking, C. (2009). The challenge of occupation: Describing the things people do. Journal of Occupational Science, 16(3), 140-150.

Jacobs, J. M., Cohen, A., Hammerman-Rozenberg, R., Azoulay, D., Maaravi, Y., \& Stessman, J. (2008). Going outdoors daily predicts long-term functional and health benefits among ambulatory older people. Journal of Aging and Health, 20(3), 259272. doi:10.1177/0898264308315427

Kaufman, S. R. (2000). The ageless self. In J. F. Gubrium \& J. A. Holstein (Eds.), Aging and everyday life (pp. 103-112). Oxford: Blackwell Publishers.

Lennartson, C., \& Silverstein, M. (2001). Does engagement with life enhance survival of elderly people in Sweden? The role of social and leisure activities. The Journals of Gerontology, 56B(6), S335-S342.

Maclean, J. (Ed.). (2000). At the end of the day: Ten New Zealanders in their 80s reflect on life in old age. Wellington: Steele Roberts Ltd.

Maier, H., \& Klumb, P. L. (2005). Social participation and survival at older ages: Is the effect driven by activity content or context? European Journal of Ageing, 2, 31-39. doi:10.1007/s10433-005-0018-5

Mendes de Leon, C. F. (2005). Social engagement and successful aging. European Journal of Ageing, 2, 64-66. doi:10.1007/s10433-00500020-y

Mendes de Leon, C. F., Glass, T. A., \& Berkman, L. F. (2003). Social engagement and disability in a community population of older adults: The New Haven EPESE. American Journal of Epidemiology, 157(7), 633-642. doi:DOI: 10.1093/aje/kwg028

Menec, V. H. (2003). The relation between everyday activities and successful aging: A 6year longitudinal study. The Journals of Gerontology, 58B(2), S74-S82.

Molke, D. K., Laliberte-Rudman, D., \& Polatajko, H. (2004). The promise of occupational science: A developmental assessment of an emerging academic discipline. Canadian Journal of Occupational Therapy, 71(5), 269-281.

Moorfield, J. C. (1988). Te kakano. Auckland: Longman Paul.

Nilsson, I., Lofgren, B., Fisher, A. G., \& Bernspang, B. (2006). Focus on leisure repertoire in the oldest old: The Umea 85+ study. The Journal of Applied Gerontology, 25(5), 391405. doi:10.1177/ 0733464806292861

Paillard-Borg, S., Wang, H.-X., Winblad, B., \& Fratiglioni, L. (2009). Pattern of participation in leisure activities among older people in relation to their health conditions and contextual factors: A survey in a Swedish urban area. Ageing \& Society, 29, 803-821. doi:10.1017/S0144686X08008337

Petry, H. (2003). Aging happens: Experiences of Swiss women living alone. Journal of Women and Aging, 15(4), 51-68. doi:10.1300/J074v15n04_05 
Simone, P. M., \& Haas, A. L. (2009). Cognition and leisure time activities of older adults. The Lifelong Learning Institute Review, 4, 22-28.

Stanley, M. (1995). An investigation into the relationship between engagement in valued occupations and life satisfaction for elderly South Australians. Journal of Occupational Science, 2(3), 100-114.

Statistics New Zealand. (2003). North Shore City community profile. Retrieved from http://www2.stats.govt.nz/domino/external/web/commprofiles.nsf/htmldocs/North+Sh ore+City+Community+Profile+-+Detailed+Statistics

Strain, L. A., Grabusic, C., Searle, M. S., \& Dunn, N. J. (2002). Continuing and ceasing leisure activities in later life: A longitudinal study. The Gerontologist, 42(2), 217-223.

van Manen, M. (2001). Researching lived experience: Human science for an action sensitive pedagogy (2nd ed.). London, Ontario: The Althouse Press.

Waldon, J. (2004). Oranga Kaumatua: Perceptions of health in older Maori people. Social Policy Journal of New Zealand, 23, 167-180.

Walker, R. (1990). Ka whawhai tonu matou: Struggle without end. Auckland: Penguin Books.

Wilcock, A. A. (1991). Occupational science. British Journal of Occupational Therapy, 54, 297-300.

Wright-St Clair, V., Kerse, N., \& Smythe, L. (2011). Doing everyday occupations both conceals and reveals the phenomenon of being aged Australian Occupational Therapy Journal, 58, 88-94. doi:10.1111/j.1440-1630.2010.00885.x 